\title{
Slowed motor conduction in lumbosacral nerve roots in cauda equina lesions: a new diagnostic technique
}

\author{
M SWASH, SJ SNOOKS \\ From The Sir Alan Parks Physiology Unit, St Mark's Hospital, and The London Hospital, London, UK
}

SUMMARY New techniques have been developed for the electrophysiological assessment of patients with suspected cauda equina lesions using transcutaneous spinal stimulation (500-1500 V: time constant $50 \mu \mathrm{s}$ ) to measure motor latencies to the external and sphincter and puborectalis muscles from L1 and L4 vertebral levels. These latencies represent motor conduction in the S3 and S4 motor roots of the cauda equina between these levels. Similarly motor latencies can be recorded from spinal stimulation to the anterior tibial muscles (L4 and L5 motor roots). Transrectal stimulation of the pudendal nerves is used to measure the pudendal nerve terminal motor latency. In 32 control subjects, matched for age and sex, mean motor latencies from $\mathrm{L} 1$ and $\mathrm{L} 4$ spinal stimulation were $5 \cdot 5$ $\pm 0.4 \mathrm{~ms}$ and $4.4 \pm 0.4 \mathrm{~ms}$ (mean $+\mathrm{SD}$ ). In the 10 patients with cauda equina disease including ependymoma, spinal stenosis, arachnoiditis and trauma, these latencies were $7 \cdot 2 \pm 0.8 \mathrm{~ms}$ and 4.6 $\pm 0.9 \mathrm{~ms}$, a significant increase in the L1 latency. The L1/L4 latency ratios to the puborectalis muscle were $1.36 \pm 0.09$ in control subjects and $1.72 \pm 0.13$ in cauda equina patients. Pudendal nerve terminal motor latencies were normal in eight of the 10 patients with cauda equina disease. The single fibre EMG fibre density in the external anal sphincter muscle (normal, $1 \cdot 5 \pm 0 \cdot 16$ ) was increased in patients with cauda equina lesions $(1.73 \pm 0.28)$, but was increased more than two standard deviations from the mean only in three patients. This increase in fibre density was not of diagnostic value since it was also found in two of the four patients with low back pain. Slowing of motor conduction in the cauda equina is thus a useful indication of damage to these intraspinal motor roots. These investigations can be used in the selection of patients for myelography, and to follow progress in patients managed conservatively.

Diagnosis of cauda equina lesions by myelography is appropriate if surgical treatment is likely, but in many patients with suspected cauda equina disease, (for example in patients with lumbosacral canal stenosis), symptoms are often not sufficiently severe to warrant surgical decompression. Adequate methods for electrophysical diagnosis would improve management by providing evidence to support the clinical diagnosis and thus to justify interventional investigation at an appropriate time.

In investigations of the pathogenesis of idiopathic neurogenic faecal incontinence ${ }^{12}$ we have developed new electrophysiological methods that can also be used in the investigation of patients with cauda equina disease, in whom incontinence is also a fre-

Address for reprint requests: M Swash, The London Hospital, Whitechapel, London E1 1BB, UK.

Received 28 June 1985 and in revised form 4 November 1985. Accepted 9 November 1985 quent problem. In patients with idiopathic neurogenic incontinence the pudendal nerve terminal motor latency (PNTML), measured by an intra-rectal stimulation technique, is increased. ${ }^{3} \mathrm{~A}$ similar increase in the terminal motor latency in the perineal branch of the pudendal nerve is a feature of patients with idiopathic stress urinary incontinence. ${ }^{45} \mathrm{We}$ have applied another new technique, transcutaneous spinal stimulation, to measure the latencies from stimulation of lower sacral motor roots in the spinal canal at the L1 and L4 vertebral levels ${ }^{367}$ using a modification of the method developed by Merton and Morton $^{8}$ for transcutaneous stimulation of the human cerebral cortex. We have previously used this technique to measure the motor conduction velocity in the spinal cord in humans, and have shown that this is slowed in some patients with demyelinating diseases. ${ }^{9}$ In this paper we show how these relatively non-invasive electrophysiological methods can be used in the diagnosis of patients with cauda equina lesions of various causes. 
Table 1 Clinical and electrophysiological date in patients with suspected cauda equina lesions (normal values in brackets)

\begin{tabular}{|c|c|c|c|c|c|c|c|c|}
\hline \multirow[t]{2}{*}{ No } & \multirow[t]{2}{*}{$\begin{array}{l}\text { Age (yr) } \\
\text { sex }\end{array}$} & \multicolumn{2}{|c|}{$\begin{array}{l}\text { Spinal latency } \\
\text { (ms) puborectalis }\end{array}$} & \multirow{2}{*}{$\frac{\begin{array}{l}\text { L1-LA } \\
\text { difference }\end{array}}{(3 \cdot 7 \pm 0.5) \dagger}$} & \multirow{2}{*}{$\begin{array}{l}\text { Spinal latency ratio } \\
(S L R) \text { puborectalis } \\
(1 \cdot 3 \pm 0 \cdot 1) \dagger\end{array}$} & \multirow{2}{*}{$\begin{array}{l}\text { Pudendal nerve } \\
\text { terminal motor } \\
\text { latency (ms) } \\
(2 \cdot 1 \pm 0 \cdot 2) \dagger\end{array}$} & \multirow{2}{*}{$\begin{array}{l}\text { Fibre density } \\
\text { external anal } \\
\text { sphincter } F D \\
(1.5 \pm 0.16) \dagger\end{array}$} & \multirow[t]{2}{*}{ Final diagnosis } \\
\hline & & $\begin{array}{l}L I \\
(4 \cdot 8\end{array}$ & LA & & & & & \\
\hline 1 & $24 M$ & $6 \cdot 8$ & $4 \cdot 6$ & $2 \cdot 2$ & 1.48 & - & - & $\begin{array}{l}\text { Cauda equina bullet wound. Double } \\
\text { incontinence }\end{array}$ \\
\hline 2 & $34 \mathrm{~F}$ & $5 \cdot 8$ & $3 \cdot 0$ & $2 \cdot 8$ & $1.93^{*}$ & $2 \cdot 0$ & $1 \cdot 7$ & $\begin{array}{l}\text { Anterior sacral meningocele stress } \\
\text { incontinence with sensory perianal } \\
\text { impairment on the right }\end{array}$ \\
\hline 3 & $51 \mathrm{M}$ & 4.9 & $2 \cdot 8$ & $2 \cdot 1$ & $1 \cdot 70^{*}$ & $1 \cdot 6$ & $1 \cdot 7$ & $\begin{array}{l}\text { Spinal stenosis. Previous L5/S1 } \\
\text { laminectomy }\end{array}$ \\
\hline 4 & $52 \mathrm{~F}$ & 6.4 & $3 \cdot 8$ & $2 \cdot 8$ & $1 \cdot 68^{*}$ & $2 \cdot 4$ & $2 \cdot 4$ & $\begin{array}{l}\text { Cauda equina tumour. Double } \\
\text { incontinence }\end{array}$ \\
\hline 5 & $55 \mathrm{M}$ & $9 \cdot 2$ & $6 \cdot 0$ & $3 \cdot 2$ & $1 \cdot 53^{*}$ & $2 \cdot 9$ & 1.8 & $\begin{array}{l}\text { Spinal stenosis. Previous L5/S1 } \\
\text { laminectomy }\end{array}$ \\
\hline 6 & $59 \mathrm{~F}$ & $6 \cdot 3$ & $3 \cdot 5$ & $2 \cdot 8$ & $1 \cdot 80^{*}$ & 1.9 & $1 \cdot 5$ & $\begin{array}{l}\text { Spinal stenosis. Previous L4/L5 } \\
\text { laminectomy }\end{array}$ \\
\hline .7 & $61 \mathrm{M}$ & $6 \cdot 1$ & 3.4 & $2 \cdot 7$ & $1 \cdot 79 *$ & 1.8 & $1 \cdot 3$ & $\begin{array}{l}\text { Low back pain-arachnoiditis. } \\
\text { Previous L5/S1 laminectomy }\end{array}$ \\
\hline 8 & $63 \mathrm{~F}$ & $6 \cdot 7$ & $4 \cdot 0$ & $2 \cdot 7$ & $1.67^{*}$ & $2 \cdot 2$ & $1 \cdot 7$ & $\begin{array}{l}\text { Spinal stenosis and faecal } \\
\text { incontinence. Previous L4/L5 } \\
\text { laminectomy }\end{array}$ \\
\hline $\begin{array}{r}9 \\
10 \\
11 \\
12 \\
13 \\
14\end{array}$ & $\begin{array}{l}70 \mathrm{~F} \\
71 \mathrm{~F} \\
60 \mathrm{M} \\
60 \mathrm{~F} \\
64 \mathrm{~F} \\
69 \mathrm{M}\end{array}$ & $\begin{array}{l}5 \cdot 8 \\
7 \cdot 3 \\
6 \cdot 0 \\
7 \cdot 0 \\
6 \cdot 2 \\
6 \cdot 0\end{array}$ & $\begin{array}{l}3 \cdot 8 \\
4 \cdot 0 \\
4 \cdot 5 \\
5 \cdot 0 \\
5 \cdot 2 \\
4 \cdot 4\end{array}$ & $\begin{array}{l}2 \cdot 0 \\
3 \cdot 3 \\
1 \cdot 5 \\
2 \cdot 0 \\
1 \cdot 0 \\
1 \cdot 6\end{array}$ & $\begin{array}{l}1 \cdot 53^{*} \\
1.82^{*} \\
1.33 \\
1.40 \\
1.20 \\
1.36\end{array}$ & $\begin{array}{l}1 \cdot 9 \\
3 \cdot 1 \\
2 \cdot 8 \\
2 \cdot 6 \\
2 \cdot 7 \\
1 \cdot 8\end{array}$ & $\begin{array}{l}1.9 \\
1.7 \\
2.5 \\
1.8 \\
1.7 \\
1.7\end{array}$ & $\begin{array}{l}\text { Spinal stenosis. Lumbar spondylosis } \\
\text { Spinal stenosis. Perianal pain } \\
\text { Low back pain. Normal myelogram } \\
\text { Low back pain. Normal myelogram } \\
\text { Low back pain. Normal myelogram } \\
\text { Low back pain. Normal myelogram }\end{array}$ \\
\hline
\end{tabular}

*Increased SLR.

†Mean + SD.

\section{Patients}

Two groups of patients were studied. A control group (Group C) consisted of 20 women and 12 men aged 23 to 70 (mean 46) years with minor anorectal disorders, such as colonic or rectal polyps ${ }^{9}$ without neurological disease. Group N (neurological disease) consisted of consecutively referred patients with suspected cauda equina disease aged 24 to 71 (mean 56) years; six of these patients were women. In 10 there were clinical signs of a cauda equina lesion (table 1). Six of these patients had lumbosacral canal stenosis, four of whom had been treated previously by laminectomy; one had a bullet wound of the cauda equina; one had an ependymoma of the cauda equina; one had sacral agenesis with anterior sacral meningocele, and one had low back and leg pain due to arachnoiditis. Three of these patients were incontinent (table 1); case 1, with cauda equina bullet wound, and case 4 , with cauda equina tumour, had both urinary and faecal incontinence. Case 2 has stress incontinence of urine. Four patients (Cases 11-14) had severe, persistent low back pain and sciatic pain without abnormal neurological signs. All the 14 patients in Group $\mathrm{N}$ had myelography, and abnormalities were found in all but the four patients with low back pain. The latter were included in this study because they had been referred for neurological investigation as cases of suspected lumbosacral canal stenosis.

Ethical consent The methods used in this study were approved by the Combined Ethical Committee of St Mark's and St Bartholomew's Hospital, and by the Ethical Committee of The London Hospital. Informed consent was obtained from each patient and control subject. Patients using cardiac pacemakers, or other electrical stimulation devices have been excluded from all our studies in which transcutaneous spinal stimulation has been used. ${ }^{9}$

\section{Methods}

Transcutaneous spinal stimulation Direct electrical stimulation of the cauda equina was achieved by transcutaneous spinal stimulation. ${ }^{389}$ The patient was placed in the left lateral position and a separate ground electrode was connected from the right upper thigh to the preamplifier of the EMG apparatus. Single shocks of 500 to $1500 \mathrm{~V}$, of $0.5 \mathrm{~ms}$ duration, delaying with a time constant of $50 \mu \mathrm{s}$, were delivered through two $1 \mathrm{~cm}$ diameter, saline-soaked gauze pads with the cathode at the level of the spinous process of the 1st and 4th lumbar vertebra respectively. The anode was directed cranially. An initial $500 \mathrm{~V}$ stimulus was applied, and increased in $200 \mathrm{~V}$ increments until the amplitude and latency of the evoked muscle response recorded in the pelvic floor sphincter muscles did not change with further stimulus increments, thus indicating that the stimulus was supramaximal. Three consecutive traces made at stimulus voltages about $20 \%$ greater than this level were recorded and used for measurement of the latency of the response.

The $\mathrm{Ll}$ and $\mathrm{L} 4$ vertebral levels of stimulation were chosen to represent the conus medullaris and the lumbosacral nerve roots of the cauda equina respectively. With our stimulator it is not possible reliably to stimulate these nerve roots at a more caudal level, presumably because of attenuation of current by the bony mass of the sacrum. ${ }^{9}$ We chose to record responses in the pelvic floor sphincter muscles because these muscles are innervated by the S3 and S4 motor roots, thus representing the most caudal parts of the motor system. ${ }^{10}$ Since the external anal sphincter is innervated by the inferior 


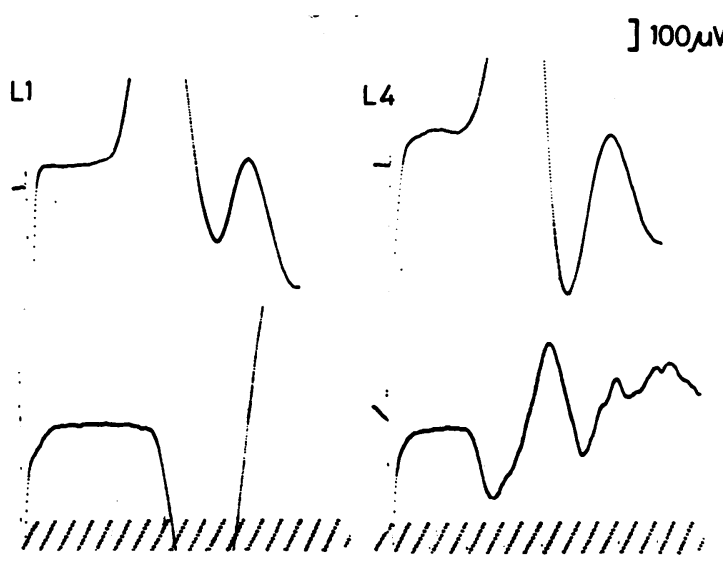

Fig 1 Case 8; responses of the puborectalis muscle after stimulation (lower traces). The L1 latency is increased and the L4 latency is normal. The upper traces are from a control subject. The trace at bottom right is depicted at $50 \%$ gain to illustrate the configurations of muscle action potential obtained with this technique.

rectal branches of the pudendal nerves, and the puborectalis largely by direct branches of the S3 and S4 motor roots, ${ }^{11}$ the compound muscle action potential responses evoked in these muscles were studied separately. All the latencies were measured independently by two observers, one of whom (SJS) carried out the electrophysiological tests. The other investigator was unaware of the clinical indication for the test or whether control or disease subjects were under investigation.

The stimulus electrodes, situated on the skin overlying the cauda equina, are several centimetres distant from the underlying excitable nervous tissue, so that the precise point of stimulation of nerve roots is not necessarily represented by the surface marking of the cathode. However, this error is probably similar at the two sites of stimulation. ${ }^{9}$ Measurement of the length of the cauda equina between the two cathodal stimulation points is also likely to be inaccurate because of the distance of the nerve roots from the surface markings. Desmedt and Cheron ${ }^{12}$ have commented on this problem in cadaver dissections. We have therefore preferred

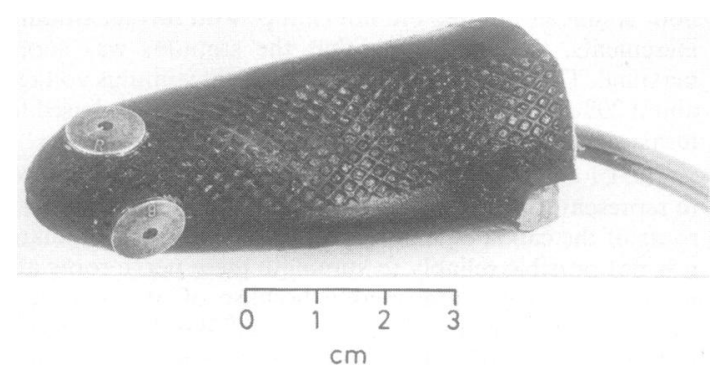

Fig 2 The intrarectal finger glove for recording the evoked contraction response of the puborectalis muscle after transcutaneous spinal stimulation. to base our interpretations of differences between control subjects and patients with suspected cauda equina lesions on latency measurements alone, without introducing additional potential errors from surface estimations of cauda equina length as would be required for conduction velocity calculations. $^{9}$

External anal sphincter response The response in the external anal sphincter muscle was recorded through two poles of a $3 \mathrm{~cm}$ long telephone jack plug electrode lubricated with electrode jelly, situated in the anal canal and connected to ground. ${ }^{39}$ The onset of the stimulus triggered the oscilloscope of the EMG machine (Medelec MS26). The latency of the response following a supramaximal stimulus was measured from the onset of the stimulus to the onset of the response. Because different recording electrodes were required, this external anal sphincter response was studied in separate recordings from the puborectalis measurements described below.

Puborectalis response Using the same technique of transcutaneous spinal stimulation the latency of the response to the puborectalis muscle was measured (fig 1 ) using a modification of our method (see below) for transrectal pudendal nerve stimulation. ${ }^{313}$ The compound muscle action potential evoked in the puborectalis muscle was recorded using a finger stall with two $1 \mathrm{~cm}$ diameter, circular, steel, surface-electrode plates, placed $1 \mathrm{~cm}$ apart, positioned at its tip $^{714}$ (fig 2). The finger bearing this device was inserted into the rectum so that the recording electrode surface was in contact with the puborectalis muscle bar; that is the recording surfaces faced posteriorly. The spinal stimulus characteristics described above were used and the contraction response of the puborectalis muscle, which could be palpated with the finger, was displayed and recorded on a Medelec MS6 EMG apparatus. The latency of this response was measured in the same way as that for the external anal sphincter muscle.

Pudendal nerve terminal motor latency (PNTML) measurement This method was developed from the technique of electroejaculation described by Brindley ${ }^{15}$ for use in patients with impotence due to paraplegia. The stimulating device consisted of a rubber finger stall having two base metal stimulating electrodes at its tip, and two metal surfacerecording electrode plates mounted $3 \mathrm{~cm}$ proximally at the base of the finger in a position suitable for picking up the compound muscle action potential of the external anal sphincter as described previously. ${ }^{313} 14$ Stimulation of the pudendal nerves on either side of the pelvis was achieved using square-wave, supra-maximal stimuli of $0.1 \mathrm{~ms}$ duration and about $50 \mathrm{~V}$. Two sets of five consecutive recordings were made at $1 \mathrm{~s}$ intervals. The latency of the response (PNTML) was measured on the paper print-out from the onset of the stimulus to the onset of the response in the external anal sphincter muscle.

Single fibre electromyography (SFEMG)

External anal sphincter muscle SFEMG of the external anal sphincter was carried out in all the patients using the method we have described previously. ${ }^{1617}$

Puborectalis muscle The technique used was based on that developed for the external sphincter muscle, using standard EMG equipment and SFEMG needle electrodes. ${ }^{17}$ The puborectalis muscle was approached from a point $1.5 \mathrm{~cm}$ posterior to the anal verge, angling the electrode anteriorly 
Table 2 Electrophysiological results

\begin{tabular}{|c|c|c|c|c|}
\hline & \multicolumn{2}{|c|}{ Suspected cauda equina lesions } & \multicolumn{2}{|c|}{ Control subjects } \\
\hline & $\begin{array}{l}\text { Cases with increased SLR } \\
n=9\end{array}$ & $\begin{array}{l}\text { Cases with normal SLR } \\
n=5\end{array}$ & $\begin{array}{l}\text { Female } \\
n=20\end{array}$ & $\begin{array}{l}\text { Male } \\
n=12\end{array}$ \\
\hline $\begin{array}{l}\text { Physiological measurement } \\
\text { Spinal latency ratio (SLR) } \\
\text { Spinal latency (ms) }\end{array}$ & $\begin{array}{l}\text { Mean SD } \\
1 \cdot 72 \pm 0 \cdot 3\end{array}$ & $\begin{array}{l}\text { Mean SD } \\
1.36 \pm 0.09\end{array}$ & $\begin{array}{l}\text { Mean SD } \\
1 \cdot 30 \pm 0 \cdot 10\end{array}$ & $\begin{array}{l}\text { Mean SD } \\
1.35 \pm 0.09\end{array}$ \\
\hline $\begin{array}{l}\text { Puborectalis L1 } \\
\text { L4 } \\
\text { External anal L1 } \\
\text { Sphincter L4 } \\
\text { Pudendal nerve terminal motor }\end{array}$ & $\begin{array}{ll}6.5 & \pm 1.1^{*} \\
3.8 & \pm 0.9 \\
7.2 & \pm 0.8 \\
4.6 & \pm 0.9\end{array}$ & $\left.\begin{array}{ll}6.2 & \pm 0.4^{*} \\
4.6 & \pm 0.4^{*} \\
7.2 & \pm 1.2^{*} \\
5.4 & \pm 1.0\end{array}\right\}(n=4)$ & $\begin{array}{ll}4 \cdot 8 & \pm 0 \cdot 4 \\
3 \cdot 7 & \pm 0 \cdot 5 \\
5 \cdot 5 & \pm 0 \cdot 4 \\
4 \cdot 4 & \pm 0.4\end{array}$ & $\begin{array}{ll}4.9 & \pm 0.4 \\
3.6 & \pm 0.4 \\
5.6 & \pm 0.4 \\
4.4 & \pm 0.4\end{array}$ \\
\hline $\begin{array}{l}\text { latency (ms) } \\
\text { Single fibre EMG. Fibre density }\end{array}$ & $2.2 \pm 0.5 \dagger$ & $3 \cdot 1 \pm 1 \cdot 4$ & $2 \cdot 1 \pm 0.2$ & $2.0 \pm 0.2$ \\
\hline $\begin{array}{l}\text { Puborectalis } \\
\text { External anal sphincter }\end{array}$ & $\begin{array}{l}1.52 \pm 0.15 \\
1.73 \pm 0.28 \dagger\end{array} \quad(n=4)$ & $\begin{array}{ll}1.62 \pm 0.12 & (n=2) \\
1.92 \pm 0.34 & (n=4)\end{array}$ & $\begin{array}{l}1.51 \pm 0.13 \\
1.50 \pm 0.19\end{array}$ & $\overline{1 \cdot 5} \pm 0.13$ \\
\hline
\end{tabular}

*Significant difference from control $\mathrm{p}<0.01$ Wilcoxon Rank Sum Test.

†Excluding case 1 .

in the midline so as to enter the puborectalis muscle. Correct placement of the electrode tip was confirmed by digital examination of the rectum. Single muscle fibre action potentials were recorded when the electrode tip was at least $2 \mathrm{~cm}$ beneath the surface of the skin, the external anal sphincter muscle being more superficially situated. Six of the fourteen patients were studied in this way.

Statistical method The Wilcoxon Rank Sum Test was used to compare data between different groups.

\section{Results}

\section{Control subject}

The means and standard deviations of motor latencies in the pelvic floor muscles from L1 and L4 spinal stimulation, PNTML measurements and SFEMG

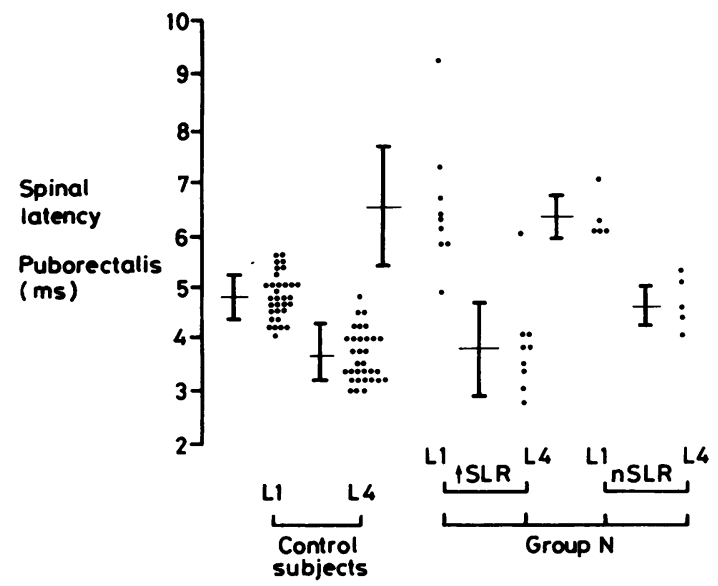

Fig 3 Distribution of the LI and LA spinal latencies to the puborectalis muscle in control subjects and patients with suspected cauda equina disease (N) with increased (SLR) and normal (nSLR) values. fibre densities for the control subjects are shown in tables 1 and 2, and in figs 3 and 4 . The Spinal Latency Ratio (SLR) was also calculated (fig 5). ${ }^{46}$

The SLR is represented by:

SLR $=\frac{\text { Latency to puborectalis after spinal stimulation at L1 }}{\text { Latency to puborectalis after spinal stimulation at L4 }}$

The SLR represents a comparison of these two latencies from different levels of transcutaneous spinal stimulation. In the presence of distal conduction delay both $\mathrm{L} 1$ and $\mathrm{L} 4$ latencies increase similarly, since the abnormal zone of nerve conduction is con-

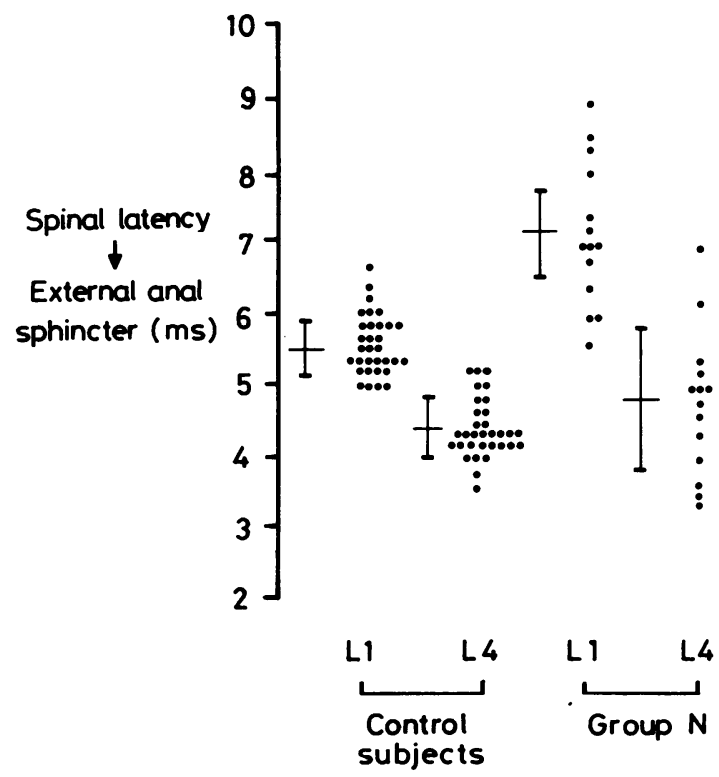

Fig 4 Distribution of the LI and L4 spinal latencies to the external anal sphincter muscle in control subjects and patients with suspected cauda equina disease $(N)$. 


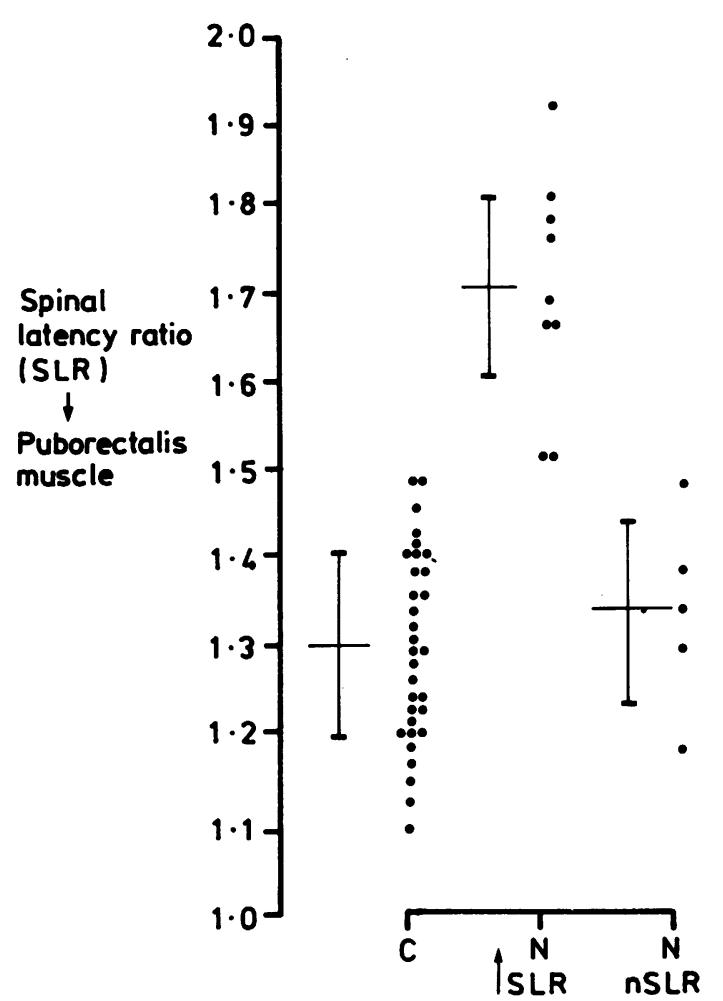

Fig 5 Distribution of the Spinal Latency Ratio (SLR) values to the puborectalis muscle in control subjects and patients with suspected cauda equina disease $(N)$.

tained in both measurements, and therefore the SLR will become slightly smaller. However, in the case of proximal conduction delay due to a lesion situated between the $\mathrm{L} 1$ and $\mathrm{L} 4$ vertebral levels the $\mathrm{L} 1$ latency will be more increased compared to the $L 4$ latency and consequently the SLR value will be increased. Stimulation at these two vertebral sites can thus be used to determine whether there is conduction delay within or distal to the $\mathrm{Ll} / \mathrm{L} 4$ portion of the cauda equina. The SLR is also increased in patients in whom there is slowed motor conduction both proximally and distally since the increased proximal (terminal motor) latency is then contained only in the measurement from the L1 stimulus. ${ }^{46}$ The variance of the SLR between subjects is relatively small. ${ }^{46}$ In women the SLR to the puborectalis from $\mathrm{L} 1$ and L4 stimulation was $1.3 \pm 0.1$ (SD), and in men it was $1.35 \pm$ 0.09 (SD) (see table 1).

We have shown elsewhere that eonduction velocity in the lower sacral motor roots of the cauda equina between $\mathrm{L} 1$ and $\mathrm{L} 4$ vertebral levels is $58 \pm 10 \mathrm{~m} / \mathrm{s}^{9}{ }^{9}$
- Group N : $r=0.56, p<0.05$ (increased SLR)

- Control group : $r=0.7, p<0.001$

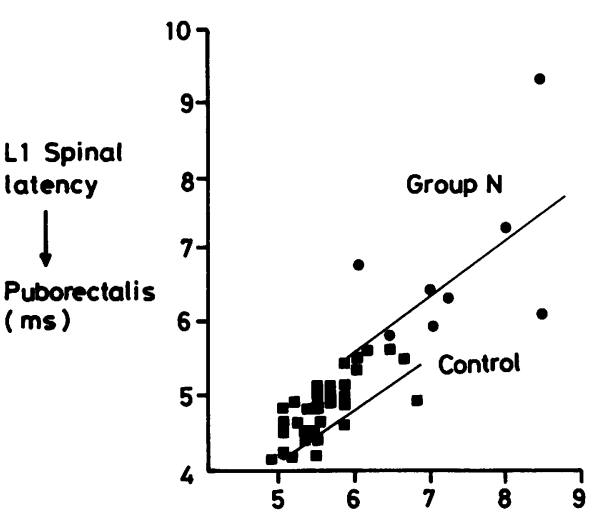

L1 Spinal latency $\rightarrow$ External anal sphincter (ms)

Fig 6 Correlation between the spinal latencies from $L 1$ stimulation, to the puborectalis and external anal sphincter muscles, in control subjects (filled squares) and patients with suspected cauda equina disease (filled circles) and increased $S L R$ values.

However, we believe the SLR is preferable to conduction velocity measurements because it avoids the introduction of potential errors in measurements of length of the spinal column between two vertebral spinal stimulation sites. We have discussed the statistical basis of this ratio (SLR) in more detail elsewhere. ${ }^{46}$

\section{Group N: Suspected cauda equina disorders}

Nine of the 10 patients had increased SLR values (table 1: fig 5). In these patients the L1 spinal latency to both the puborectalis and external anal sphincter muscles was increased (figs 3 and 4), but the latency from L4 spinal stimulation, and the PNTML were normal. The SFEMG fibre density was normal in the puborectalis muscle in the four patients in this subgroup in whom this test was performed, but it was increased in the external anal sphincter in nine patients. In case 1 no motor unit potentials could be recorded in the latter muscle.

In the four patients with back pain and normal myelograms, the SLR was normal. In these patients both the $\mathrm{L} 1$ and L4 spinal latency measurements were increased (figs 3 and 4), but this was commensurate with the increased PNTMLs found in these patients, suggesting a distal lesion (table 2: figs 3 and 4). The fibre density was increased in both the puborectalis and external anal sphincter muscles in two of these patients; and the PNTML was increased in three of these four patients. 

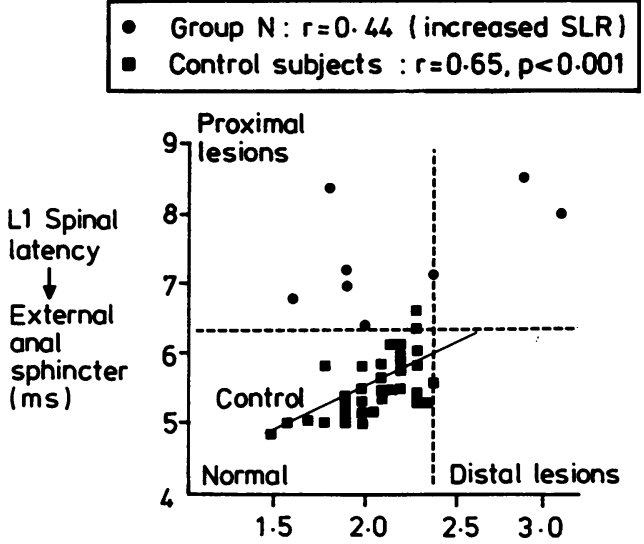

Pudendal nerve terminal motor latency (ms)

Fig 7 Correlation of the spinal latency from L1 spinal stimulation to the external anal sphincter muscle, in control subjects (filled squares) and patients with suspected cauda equina disease (filled circles) and increased SLR values.

\section{Correlation of spinal motor latencies and PNTML measurements}

In the 32 control subjects there was a significant correlation $(\mathrm{r}=0.82, \mathrm{p}<0.01)$ between the spinal motor latencies from $\mathrm{Ll}$ to the puborectalis and external anal sphincter muscles (fig 6). A less significant correlation was observed in the patients in Group N ( $r=0.56, p<0.05)$. In patients in Group $\mathrm{N}$, with an increased SLR $(\mathrm{r}=0.44, \mathrm{p}>0.1)$ there was no correlation between the L1 spinal latency to the external anal sphincter muscle and the PNTML measurements (fig 7). In six of these nine patients (table 1) distal motor conduction was normal. In three of these patients (cases 4, 5 and 10) and in three of the four patients with low back pain, normal myelogram and normal SLR, the PNTML, representing distal motor conduction was increased.

\section{Illustrative case reports}

The relevance of these electrophysiological results in the diagnosis of patients with suspected cauda equina disease is illustrated in the following cases.

Case 1 (table 1) Bullet wound to cauda equina This 24-year-old soldier had sustained a bullet wound to the sacrum at the S1 level 9 months previously, causing double incontinence and impotence. Examination revealed sensory loss in right $\mathbf{S} 2$ to $\mathrm{S} 5$ and in left $\mathrm{S} 3$ to S5 dermatomes. The right angle jerk was absent; the left was just present. Both knee jerks were brisk and plantar responses were flexor. Slight weakness of right plantar flexion and knee flexion was noted. The perineum was weak, with anal eversion and perineal descent on straining to defaecate. The anal reflexes were absent; the cremasteric reflexes were present.

Electrophysiological studies revealed normal latencies from spinal stimulation at $\mathrm{L} 1$ and $\mathrm{L} 4$, recorded at the right tibialis anterior muscle $(11.5$ and $10.0 \mathrm{~ms}$ respectively). ${ }^{9}$ Transrectal pudendal nerve stimulation failed to elicit a response from the external anal sphincter muscle, and no motor unit activity was recorded by SFEMG needle electrodes. The spinal motor latency from $\mathrm{Ll}$ to the puborectalis muscle was increased $(6.8 \mathrm{~ms})$, as was that from L4 stimulation $(4.6 \mathrm{~ms})$, giving an SLR in the upper part $(1.48)$ of the normal range $(<1.53)$. No external anal sphincter muscle response to spinal or pudendal stimulation could be recorded. The SLR to the right tibialis anterior muscle (L5 root) was within the normal range $(1 \cdot 15)$. These results indicated that there was an abnormality within the sacral motor roots innervating the pelvic floor musculature. Radiographs of the pelvis and sacral spine showed a vertical fracture in the bony mass of the sacrum in the midline at the S1 level, and a myelogram showed that the theca was cut off and did not fill below this level. It was concluded that the bullet had directly injured this region and exploration was not advised.

Case 4 (table 1) cauda equina ependymoma This 52-year-old woman presented with double incontinence of 5 months duration. She had experienced dull lumbar pain during the same period. For 6 weeks she had noticed numbness of her buttocks and loss of urethral and anorectal sensation. On examination there was no voluntary contraction of the external anal sphincter muscle and the anal reflex was absent. There was loss of sensation in S2 and S5 dermatomes bilaterally, but tendon reflexes in the legs were normal and plantar responses were flexor.

Electrophysiological studies (table 1) showed an increased spinal motor latency to the puborectalis muscle from Ll $(6.4 \mathrm{~ms})$, but not from L4 stimulation $(3.8 \mathrm{~ms})$. The PNTML was not significantly increased $(2.4 \mathrm{~ms}$; normal $2.1 \pm 0.2 \mathrm{~ms})$. The fibre density in the external anal sphincter muscle was markedly increased (2.4). A lumbar myelogram showed a complete block at L2 level and laminectomy revealed an ependymoma. The tumour was resected and radiation therapy was given. During the next 9 months there was gradual improvement in her incontinence and also to some degree in the saddle distribution sensory disturbance, but the pelvic floor remained weak.

Case 8 (table 1) lumbosacral canal stenosis This 63-year-old woman presented with anorectal incontinence of three years duration with low back pain. Twenty years previously she had undergone L4/L5 and L5/S1 laminectomies for sciatica after Myodil myelography revealed disc protrusions. Examination showed impaired sensation in the perineum and in L5 and $\mathrm{Sl}$ dermatomes bilaterally, and the anal reflexes 


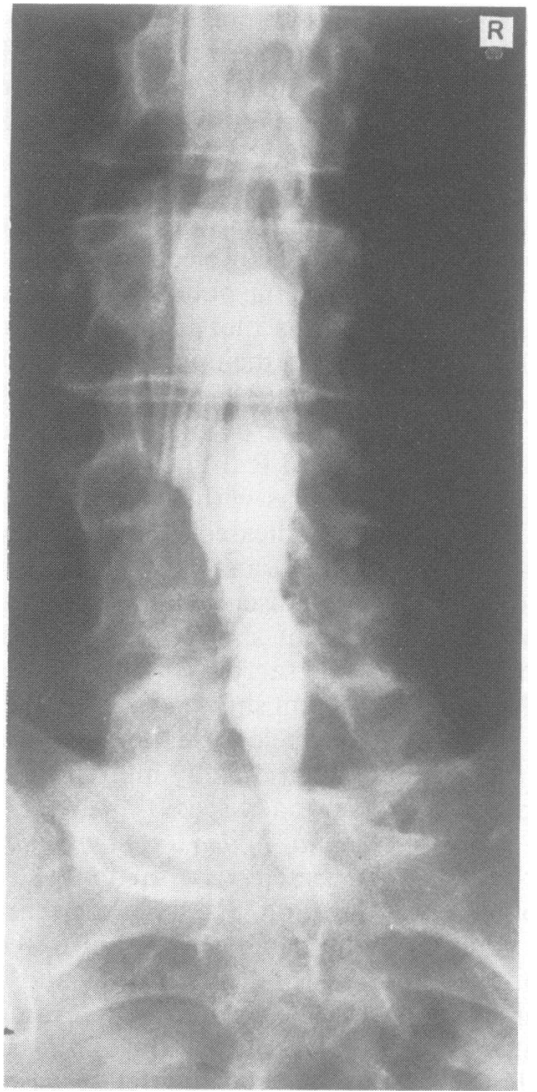

Fig 8 Case 8; lumbosacral myelogram (Iohexol) showing narrowing and irregularity of the theca.

and ankle jerks were absent. There was perineal descent on straining to defaecate. Straight leg raising was restricted to $20^{\circ}$ bilaterally. There was slight weakness of ankle eversion on the left. Both plantar responses were flexor.

Electrophysiological studies revealed an increased L1 spinal latency to the puborectalis muscle $(6.7 \mathrm{~ms})$, a normal L4 spinal latency to the puborectalis muscle $(4.0 \mathrm{~ms})$ and an increased SLR $(1.7)$ consistent with cauda equina conduction delay (fig 2). The SFEMG fibre density was only slightly increased in the external anal sphincter muscle and the PNTML was within normal limits. These results suggested a proximal lesion. A myelogram (fig 8) with CT scanning of the lumbosacral region (fig 9) showed narrowing and irregularity of the theca with loss of root pouches and tethering of the nerve roots in relation to residual droplets of Myodil. These appearances were consistent with arachnoiditis.

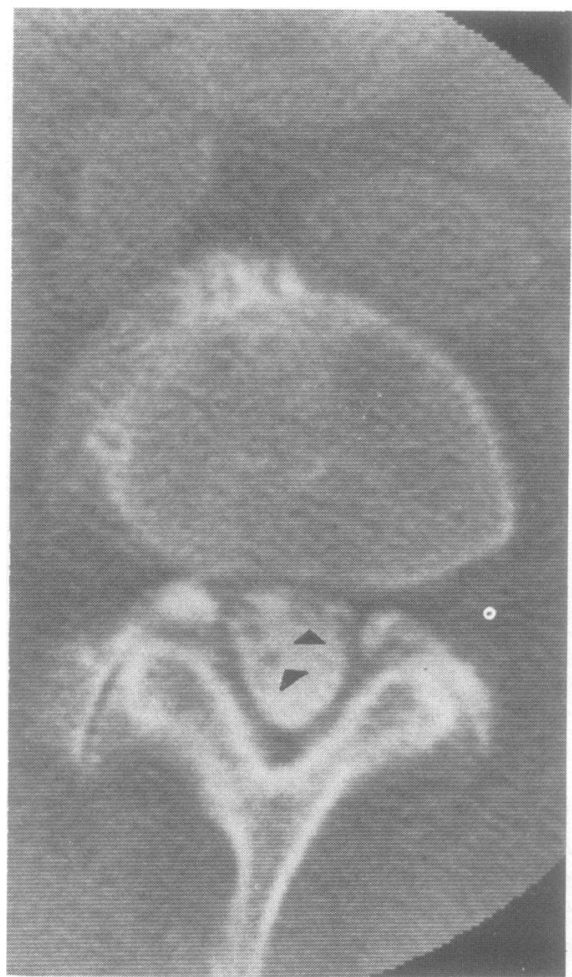

Fig 9 Case 8; CT scan (Dr D Kingsley) of the lumbosacral region showing displacement (arrow) of the nerve roots (with lohexol contrast).

\section{Discussion}

The electrophysiological methods described in this report enable a quantitative assessment to be made of distal motor nerve conduction in the pudendal innervation of the external anal sphincter muscle, and of proximal conduction in the motor nerve roots of the cauda equina that innervate the puborectalis and external anal sphincter muscles. These investigations thus test motor conduction in the S3 and S4 motor roots. The single fibre EMG density in the external anal sphincter and puborectalis muscles ${ }^{1718}$ can be used as an index of reinnervation in these muscles. ${ }^{1619}$ This interpretation is supported by histopathological studies of these muscles that show features consistent with denervation and reinnervation. ${ }^{20}$ The validity of pelvic floor motor latency measurements from $\mathrm{Ll}$ and $\mathrm{L} 4$ spinal stimulation in the evaluation of the cauda equina is shown by the results in Case 1 in which a complete cauda equina lesion resulted from a high velocity bullet wound and similarly in the nine other patients 
investigated (table 1) because cauda equina disease was suspected (Group N). The mean spinal latencies from $\mathrm{Ll}$ to the puborectalis and external anal sphincter muscles in these patients were increased ( $p$ $<0.01$ : table 2) but the latencies from L4 were normal, indicating that there was conduction delay in the spinal canal between the $L 1$ and $L 4$ vertebral levels. This is illustrated in the case reports of cases 1,4 and 8 . The terminal motor latency in the pudendal nerves (PNTML) was normal in seven of the nine patients with an increased SLR (cases 2 to 10: table 1) indicating that conduction in the distal portion of the innervation of these pelvic floor muscles was normal. In two of these nine patients (cases 5 and 10: table 1) both the SLR and the PNTML were increased indicating damage to the innervation of the pelvic floor muscles both at proximal (cauda equina) and distal (pudendal) sites. In Case 1 the external anal sphincter muscle was inexcitable from stimulation at spinal or pudendal levels and the puborectalis response was delayed from L1 and L4 spinal stimulation. The innervation of puborectalis is derived from direct motor branches of the S3 and S4 motor roots ${ }^{11}$ and there must have been only partial damage to this innervation. However, the latencies to the anterior tibial muscles in this patient were normal indicating integrity of the L4 and L5 motor nerve roots in the spinal canal. These results indicate that the external anal sphincter muscle was probably denervated by a lesion at a proximal site.

The four patients with low back pain and normal myelograms (cases 11-14: table 1) showed normal SLR values, but three had an increased PNTML, and the fibre density in the external anal sphincter was increased in two. The fibre density in the puborectalis in these two patients was normal. These results indicate that in these patients the innervation of the external anal sphincter was damaged at a distal localised site; and that this was unrelated to the low back pain in these patients.

The diagnosis of cauda equina lesions is usually suggested by the combination of radicular sensory or motor disturbance, root pain and absent ankle jerks. In patients with spinal stenosis, with or without central disc prolapse, the diagnosis can usually be confirmed by myelography ${ }^{21-23}$ as in our patients in Group $N$ (cases 3, 5, 6, 8, 9 and 10: table 1), but this investigation is often uncomfortable and may, rarely, lead to persistent pain or even arachnoiditis. Adequate methods for the electrophysiological assessment of such patients would therefore be an advance in clinical management since a decision to advise myelography and thus possible surgical treatment might therefore be more firmly based. The tests described in this paper, particularly the measurement of motor latencies to the pelvic floor muscles are directly relevant to this problem since they test motor conduction in the lower sacral motor nerve roots which arise from the conus medullaris at the T12/L1 vertebral level and traverse the whole lumbosacral canal in the cauda equina in the midline en route to the $\mathrm{S} 3$ and $\mathrm{S} 4$ exit foramina in the sacral spine. We have not yet found it possible to stimulate consistently the sacral nerve roots at a lower vertebral level than L4 or L5 using our transcutaneous technique, probably because of the thickness of the bone of the spinal column, and the distance of the nerve roots from the stimulating electrodes at these caudal sites. Nonetheless these new techniques are of practical value in the management of this clinical problem. The stimulus is delivered by a condenser discharge. ${ }^{9}$ Spinal stimulation is a safe procedure, although it requires higher voltages than ordinarily used in clinical neurophysiological laboratories. The current flow is not large since the stimulus is of very brief duration. We have encountered no untoward effects in several hundred investigations ${ }^{34-7914}$ and none has been reported by other investigators using a similar technique for scalp stimulation. ${ }^{89}$ We have avoided using this form of electrical stimulation in patients with cardiac pacemakers or other nerve stimulating devices and would not recommend it in patients with vertebral metastatic cancer.

\section{References}

${ }^{1}$ Parks AG. Anorectal incontinence. Proc $R$ Soc Med 1975;68:681-90.

${ }^{2}$ Beersiek F, Parks AG, Swash M. Pathogenesis of anorectical incontinence: a histometric study of the anal sphincter musculature. $J$ Neurol Sci 1979;42:111-27.

${ }^{3}$ Kiff ES, Swash M. Normal proximal and slowed distal conduction in the pudendal nerves of patients with idiopathic (neurogenic) faecal incontinence. $J$ Neurol Neurosurg Psychiatry 1984;47:820-3.

${ }^{4}$ Snooks SJ, Swash M. Abnormalities of the innervation of the urethral striated sphincter musculature in incontinence. Br J Urol 1984;56:401-5.

${ }^{5}$ Snooks SJ, Badenoch D, Tiptaft R, Swash M. Perineal nerve damage in genuine stress incontinence of urine: an electrophysiological study. Br J Urol 1985;57:422-6.

${ }^{6}$ Snooks SJ, Swash M. Perineal nerve and transcutaneous spinal stimulation: new methods for the investigation of the urethral striated sphincter musculature. $B r J$ Urol 1984;56:406-9.

${ }^{7}$ Snooks SJ, Barnes PRH, Swash M. Damage to the innervation of the voluntary anal and periurethral musculature in incontinence. $J$ Neurol Neurosurg Psychiatry 1984;47:1269-73.

${ }^{8}$ Merton PA, Morton HB. Stimulation of the cerbral cortex in the intact human subject. Nature 1980;285:227.

${ }^{9}$ Snooks SJ, Swash M. Motor conduction velocity in the human spinal cord: slowed conduction in multiple sclerosis and radiation myelopathy. $J$ Neurol Neurosurg 
Psychiatry 1985;48:1135-9.

${ }^{10}$ Sherrington CS. Notes on the arrangement of some motor fibres in the lumbosacral plexus. J Physiol (London) 1882;13:672-5.

${ }^{11}$ Percy JP, Neill ME, Swash M, Parks AG. Electrophysiological study of motor nerve supply of the pelvic floor. Lancet 1981;i:16-17.

${ }^{12}$ Desmedt JE, Cheron G. Spinal and far field components of human somatosensory evoked potentials to posterior tibial nerve stimulation analysed with oesophageal derivations and non-cephalic reference recording. Electroencephalogy Clin Neurophysiol 1983;56:635-51.

${ }^{13} \mathrm{Kiff}$ ES, Swash M. Slowed conduction in the pudendal nerves in idiopathic (neurogenic) faecal incontinence. Br J Surg 1984;71:614-6.

${ }^{14}$ Snooks SJ, Henry MM, Swash M. Anorectal incontinence and rectal prolapse: differential assessment of the innervation to puborectalis and external anal sphincter muscles. Gut 1985;26:470-6.

${ }^{15}$ Brindley GS. Electroejaculation: its technique, neurological implications and uses. J Neurol Neurosurg Psychiatry 1981;44:9-10.
${ }^{16}$ Stalberg ES, Trontelj V. Single Fibre Electromyography. Old Woking. Mirvalle Press, 1979.

${ }^{17}$ Neill ME, Swash M. Increased motor unit fibre density in the external anal sphincter muscle in anorectal incontinence: a single fibre EMG study. $J$ Neurol Neurosurg Psychiatry 1980;43:343-7.

${ }^{18}$ Neill ME, Swash M, Parks AG. Physiological studies of the anal sphincter musculature in faecal incontinence and rectal prolapse. Br J Surg 1981;68:531-6.

${ }^{19}$ Swash M, Schwartz MS. Neuromuscular diseases: a practical approach to diagnosis and management. New York: Springer-Verlag, 1981.

${ }^{20}$ Parks AG, Swash M, Urich H. Sphincter denervation in anorectal incontinence and rectal prolapse. Gut 1977;18:656-65.

${ }^{21}$ Blau JN, Logue V. Intermittent claudication of the cauda equina. Lancet $1981 ; \mathrm{i}: 1081-6$.

22 Joffe E, Appleby A, Arjone V. Intermittent ischaemia of the cauda equina due to stenosis of the lumbar canal. $J$ Neurol Neurosurg Psychiatry 1966;29:315-8.

${ }^{23}$ Wackenheim A, Babin E. The Narrow Lumbar Canal. Berlin: Springer-Verlag, 1980:91-5. 